\title{
Penarapan Arsitektur Ekologi Pada ObJek Wisata Edukasi Peternakan Kambing Etawa Di Kaligesing, Purworejo
}

\author{
Wulan Ratnaningsih, Wiwik Setyaningsih, Maya Andria \\ Program Studi Arsitektur \\ Jurusan Arsitektur Fakultas Teknik \\ Universitas Sebelas Maret Surakarta \\ Email : ratnaningsih.wulan@student.unc.ac.id
}

\begin{abstract}
In this era of globalization, the tourism industry is the largest contributing are in various countries in the world. The absorption of the tourism industry on employment until the year 2020 , more than $10 \%, 11 \%$ of the Global GDP, and total activity of tourist travel is projected to continue to rise to 16 billion (Speirs,2010 in Setyaningsih,2017). Indonesia is a country that has various potential nature, flora, fauna and culture that can be processed for attracting tourists. Purworejo has a potential offauna typical of the area in the form of Etawa Goat Kaligesing already known excellence quality of milk up to the many goats are exported to foreign countries such asMalaysia and Singapore. But it turns out that the existence of Etawa Goat Kaligesing not yet received special attention from the local community so many seeds out of the export practices of the country which caused the depletion of the number of seeds in etawa goat kaligesing his own origins. Based on existing problems, it takes a vessel that can accommodate the goat farm activities as etawa preservation of seedsas well as educational activities to society about the benefits and importance of preserving seeds etawa goat. To support the activities of animal husbandry and education in order to continue to be sustainable, then the activity last packed in tourism activities where the concept of designing attractions of yesteryear is by paying attention to the preservation of the surrounding environment, i.e. with the approach of Ecological Architecture.
\end{abstract}

Keywords: Tourism, Etawa Goat, Farm, Ecological Architecture, and Educational Tours.

\section{PENDAHULUAN}

Pada era globalisasi ini, industri pariwisata merupakan indutri yang menyumbangkan devisi terbesar pada berbagai negara di dunia. Penyerapan ketenagakerjaan pada industry pariwisata sampai tahun 2020 , lebih dari $10 \%, 11 \%$ GDP Global, dan total aktivitas perjalanan wisatawan diproyeksikan akan terus meningkat sampai 16 milyar (Speirs,2010 dalam Setyaningsih, 2016). Indonesia adalah sebuah negara yang memiliki beragam potensi alam, flora, fauna dan budaya yang bisa diolah untuk menarik minat wisatawan. Sementara target pemerintah sampai tahun 2019 bisa mendatangkan 20 juta wisatawan mancanegara. Target pemerintah ini sangat mungkin diwujudkan karena sesungguhnya lndonesia memiliki begitu banyak potensi alam, flora, fauna serta budaya.

Kabupaten Purworejo merupakan kabupaten di Provinsi Jawa Tengah, dengan Ibukota berada di kota Purworejo. Sektor pariwisata Kabupaten Purworejo ditopang oleh ketersediaan potensi keindahan alam, wisata sejarah, dan potensi wisata peternakan, namun hingga saat ini belum terkelola secara maksimal, sehingga masyarakat Purworejo lebih tertarik untuk mengunjungi obyek wisata lain yang berada di daerah sekitarnya. Sementara itu di Kabupaten Purworejo terdapat potensi peternakan berupa fauna 
khas daerah yaitu Kambing PE Etawa Khas Kaligesing yang dikenal sebagai kambing perah atau kambing penghasil susu dengan kualitas yang sangat baik. Karena kualitas Kambing PE Kaligesing yang baik, kambing ini sudah banyak yang dibawa ke luar daerah, keluar pulau, bahkan keluar negri. Akibat dari banyaknya praktik ekspor bibit unggul dari Kambing PE Kaligesing ini, Gubernur Jawa Tengah yang saat itu dijabat oleh Bibit Waluyo, pernah melakukan pelarangan keras kepada peternak yang menjual kambing bibit unggul ke luar negeri. Hal ini adalah akibat dari masyarakat yang kurang mendapatkan edukasi tentang pentingnya menjaga kelestarian bibit unggul.

Berdasarkan permasalahan yang ada, dibutuhkan sebuah wadah yang dapat mengakomodasi kegiatan peternakan kambing etawa sebagai usaha pelestarian bibit unggul serta kegiatan edukasi terhadap masyarakat tentang manfaat dan pentingnya pelestarian bibit unggul kambing etawa. Untuk mendukung kegiatan peternakan dan edukasi agar terus berkelanjutan, maka kegiatan tadi dikemas dalam kegiatan pariwisata dimana konsep perancangan objek wisata tadi adalah dengan memperhatikan kelestarian lingkungan sekitarnya, yaitu dengan pendekatan Arsitektur Ekologi.

Pendekatan Arsitektur Ekologi dipilih karena lokasi dari kegiatan peternakan dan pariwisata tadi berada di alam pegunungan yang apa bila dalam perancangannya kurang memperhatikan kelestaran lingkungan sekitar maka akan merusak kelangsungan hidup ekosistim di sekitar area objek wisata tersebut. Karena kelangsungan hidup bibit unggul kambing etawa kaligesing sendiri juga sangat dipengaruhi oleh keadaan alam sekitarnya.

\section{METODE}

Perancangan Objek Wisata Edukasi Peternakan Kambing Etawa bermula dari pemikiran tentang upaya dalam menciptakan suatu wadah kegiatan berupa kawasan wisata edukasi peternakan kambing etawa yang memperhatikan lingkungan sekitar.

Berikut ini adalah kriteria bangunan ekologis menururt Heinz Frick,yaitu:

1. Menciptakan kawasan hijau diantara kawasan bangunan
a. Menciptakan taman ekologis disekitar bangunan
b. Urban Farming (urban agriculture)

2. Memilih tapak bangunan yang sesuai

3. Menggunakan bahan bangunan buatan lokal

4. Orientasi bangunan ditempatkan diantara lintasan matahari dan angin sebagai kompromi antara letak gedung berarah dari timur ke barat, dan yang terletak tegak lurus terhadap arah angin.

5. Penghawaan dam pencahayaan Alami

6. Menjamin bahwa bangunan tidak menimbulkan permasalahan lingkungan

7. Menciptakan bangunan bebas hamtan (dapat digunakan semua umur dan pengguna difabel)

\section{ANALISIS}

\subsection{Analisis Pemilihan Tapak}

\subsubsection{Tujuan}

Menentukan lokasi site yang paling tepat dan sesuai untuk pembangunan objek yang direncanakan.

\subsubsection{Dasar Pertimbangan}

1. Sesuai dengan Peraturan Daerah Kabupaten Purworejo No.27 tahun 2011 tentang Rencana Tata Ruang Wilayah Kabupaten Purworejo Tahun 2011-2031.

2. Site memiliki keadaan kondisi alam yang indah yang dapat dinikmati untuk berekreasi.

3. Site merupakan lahan yang memiliki potensi yang cocok bagi kelangsungan peternakan maupun perkebunan.

4. Segi aksesibilitas, site yang dipilih adalah yang bisa dicapai 
menggunakan motor, mobil, dan bis besar.

5. Segi infrastruktur, site yang dipilih harus memiliki kondisi jalan yang cukup baik serta lebar jalan yang cukup, terdapat jaringan listrik, terdapat jaringan telepon, terdapat sumber mata air, dan infrastuktur pembuangan limbah di lingkungan site harus tersedia.

6. Berdasarkan perhitungan kebutuhan luas bangunan pada analisis besaran site.

Site yang terpilih menjadi lokasi Perancangan Objek Wisata Edukasi Peternakan Kambing Etawa di Kaligesing adalah site yang terletak di Jalan Raya Kaligesing, Tlogoguwo, Kaligesing, Purworejo. Luas site kurang lebih adalah $9200 \mathrm{~m}^{2}$. Masalah khusus yang terdapat di objek ini adalah permasalahan bau dari peternakan kambing. Sehingga untuk menanggulangi permasalahan tersebut, maka perletakan area peternakan berada di dataran yang lebih rendah, agar bau dari peternakan tidak menyebar ke fasilitas wisata lain. Selain itu sebelum menuju area peternakan juga diterapkan pepohonan dan kolam ikan yang diharapkan dapat menyaring baru limbah peternakan.

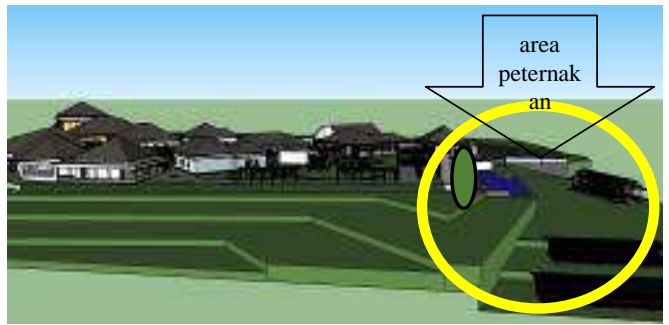

Gambar 1. Pengolahan Tapak

(Desain penulis)

\subsection{Analisis Pencapaian Tapak}

Tujuan dari analisa pencapaian ini adalah untuk mendapatkan main entrance (ME) in (masuk) dan out (keluar) dari area bangunan yang direncanakan serta adanya side entrance dan servis entrance (SE) sebagai jalan masuk menuju area servis. Dasar pertimbangan analisis pencapaian adalah sebagai berikut :

1. Sirkulasi lalu lintas sekitar site, keberadaan ME dan SE tidak menyebabkan kemacetan.

2. Menyesuaikan dengan arah pergerakan lalu lintas jalan di sekitarnya

3. Kemudahan pencapaian kendaraan dari jalan utama

4. Pertimbangan keamanan akses ke dalam dan keluar site. Pencapaian utama site yang dipilih adalah dari jalan utama di sebelah barat site yaitu Tlogoguwo. Pencapaian servis juga akan melalui jalan tlogoguwo namun melalui gerbang yang berbeda dengan gerbang pengunjung dan pengelola.

5. Area Selatan adalah area dengan pemandangan yang paling indah, sehingga area selatan akan digunakan sebagai area dimana bangunan yang membutuhkan view terbaik, sehingga jalann masuk servis lebih dititik beratkan berada di area utara.

6. Karena jalan masuk servis berada di utara, Area peternakan juga akan diletakkan pada area utara. Agar segala sesuatu yang berhubungan dengan peternakan (angkut ternak/hasil ternak/keperluan ternak) adalah melewati jalur servis ini.

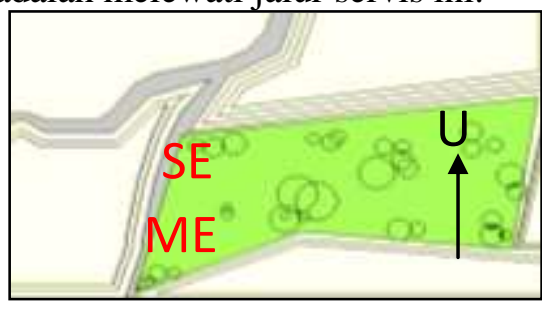

Gambar 2.Hasil Analisa Pencapaian (Analisis Penulis)

\subsection{Analisis Klimatologi}

Tujuan dari analisis klimatologis adalah untuk mengetahui aspek-aspek iklim di lingkungan site yang dapat mempengaruhi proses perencanaan dan perancangan bangunan sehingga mampu menentukan respon yang tepat terhadap 
pemecahan masalah yang mungkin timbul disebabkan keadaan ikllim setempat.

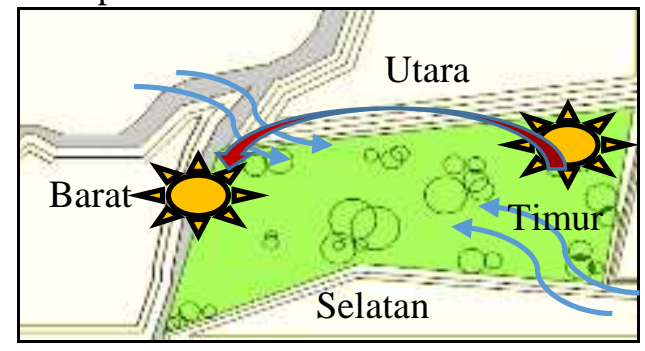

Gambar 3. Analisis Klimatologi (Analisis Penulis)

Untuk menghindari sinar matahari yang mengganggu aktivitasaktivitas tertentu, maka perlu diperhatikan dalam menempatkan bukaan-bukaan serta penempatan sunshading pada bangunan yang berada di area barat site.

Arah hembusan angin pada site adalah, melalui arah barat laut menuju tenggara, atau sebaliknya tergantung dengan pengaruh pergantian arah angin muson. Permasalahan khusus terkait klimatologi yang dimiliki oleh objek wisata edukasi peternakan kambing etawa adalah permasalahn limbah bau dari peternakan yang memerlukan perhatian khusus dalam perancangannya. Agar kondisi penghawaan di bangunan yang berada di kawasan ini tidak bercampur dengan bau peternakan dan bau dari limbah peternakan.

\subsection{Analisis Kebisingan}

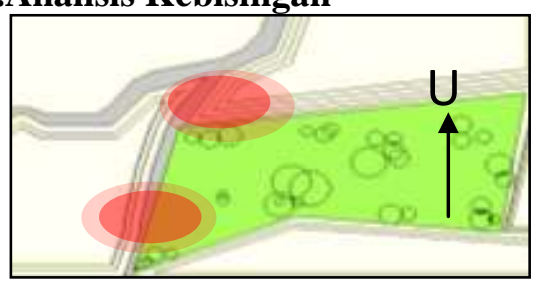

Gambar 4. Analisis Kebisingan (Analisis Penulis)

Tujuan dari melakukan analisis kebisingan adalah untuk mengetahui sumber kebisingan dan mencari solusi untuk menjaga kestabilan tingkat kebisingan agar tetap pada tingkat yang nyaman bagi penggunanya. Dasar pertimbangan analisis kebisingan adalah :
1. Arah sumber kebisingan yang ada di lingkungan site (dari luar site) yang berasal dari kendaraan.

2. Sumber kebisingan yang ditimbulkan dari dalam site. Yang berasal dari aktivitas-aktivitas tertentu yang menyebabkan kebisingan, seperti aktivitas outbond dan aktivitas bebas. Sumber kebisingan kendaraan berasal dari Jalan Tlogoguwo dan dari area parkir kendaraan pengunjung, sehingga pada area yang berada di sekitar area tersebut sebaiknya dipergunakan bagi bangunan yang bersifat tidak terlalu privat. Sementara area utara, selatan dan timur adalah area yang relatif lebih sepi karena tidak terdapat kebisingan yang berarti dari aktivitas diluar kawasan.

Kebisingan site dapat ditanggulangi dengan :

1. Penggunaan penghalang (penyaring) suara berupa pagar ataupun vegetasi yang mampu memecah suara serta mereduksinya.

2. Memberikan jarak kepada bangunan yang membutuhkan ketenangan

3. Penempatan bangunan berdasarkan zoning yang sesuai dengan tingkat ketenangan yang dibutuhkan. Yaitu dengan menempatkan ruang-ruang privat jauh dari area public yang aktivitasnya menghasilkan kebisingan yang tinggi.

4. Untuk menanggulangi kebisingan antar ruangan, maka diterapkan peletakan tanaman-tanaman penyaring kebisingan untuk meredam suara serta memberikan bukaanbukaan yang tidak terlalu banyak pada area yang menjadi sumber kebisingan.

\subsection{Analisis Orientasi dan View}

Tujuan dari analisis orientasi adalah untuk menentukan arah bangunan terhadap lingkungan sekitar. Pertimbangan analisis orientasi ini adalah : 
1. Eksisting jalan dan arah lalu lintas di jalan sekitar site.

2. Arah datang/masuknya pengunjung.

Karena site hanya memiliki 1 jalan utama yang melewati area site maka sudah jelas bahwa arah orientasi bangunan utama adalah menghadap ke barat.

Sementara,tujuan dari analisis view adalah menentukan konsep peletakan massa bangunan utama secara tepat, sehingga dapat dengan mudah dikenali oleh pengunjung dan mampu menunjang konsep desain bangunan. Selian itu analisis view ini juga bertujuan untuk menentukan letak bukaan-bukaan view yang akan berdampak pada kenyamanan dari pengguna Objek Wisata Edukasi Peternakan Kambing Etawa.

Dasar pertimbangan analisis view adalah :

1. Lokasi Main Entrance ke dalam site.

2. Arah datangnya pengguna atau pengunjung

3. Keadaan alam lingkungans sekitar yang indah

4. Bangunan bangunan disekitar site.

Analisis view ini mencakup view keluar dan view ke dalam bangunan. Analisisnya yaitu sebagai berikut :

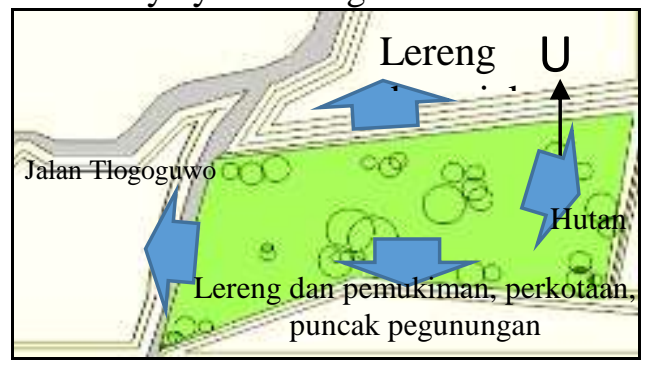

Gambar 5. Analisis View dan Orientasi (Analisis Penulis)

Berdasarkan analisis di atas, view terbaik adalah view dari arah selatan site karena akan langsung bisa menatap jauh ke perkotaan, dan puncak-puncak gunung yang tidak terhalang apapun. Selain itu di bagian selatan ini juga dimungkinkan view sunrise dan sumset bisa terlihat jelas.

\subsection{Analisis Pemintakatan (zoning)}

Analisis zona bertujuan untuk mengetahui zona setiap kelompok kegiatan sebagai pedoman dalam peletakan massa bangunan yang paling tepat sesuai dengan hasil analisis site dan kebutuhan dari tiap-tiap kelompok fungsi yang ada. Analsisi zona ini akan mempengaruhi pola tata massa bangunan dan sirkulasi pengguna bangunan.

Dasar pertimbangan analisis penzoningan ini adalah :

1. Hasil analisis program ruang

2. Hasil analisis pencapaian

3. Hasil analisis orientasi

4. Hasil analisis view

5. Hasil analisis kebisingan

6. Hasil analisisi klimatologi

Berdasarkan analsisi tersebut maka zoning yang terpilih adalah sebagai berikut :

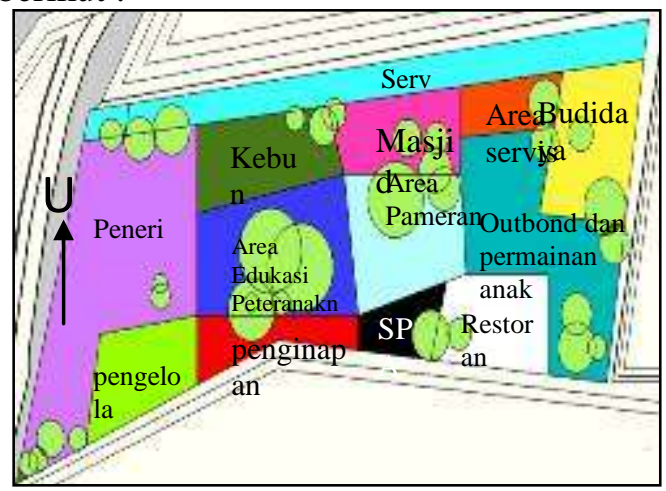

Gambar 6. Hasil analisis Zoning (Analisis Penulis)

\subsection{Analisis Tata Massa dan Fasad Bangunan}

\subsubsection{Analisis Tata Masa}

Analisis tata masa bangunan ini bertujuan untuk menentukan tata letak letak masa bangunan dalam site sesuai dengan kelompok fungsi bangunan. Analisis tata masa bangunan ini disesuaikan pula dengan konsep ekologis yang akan diterapkan. Dasar pertimbangan analisis ini adalah :

1. Hasil analisis pengelompokan penggunaan fungsi ruang pada site

2. Penataan sirkulasi pengguna antar masa bangunan

3. Hubungan antar masa bangunan

4. Keserasian/unity 
5. Optimalisasi penggunaan site

\subsubsection{Analisis Fasad Bangunan}

Konsep pengolahan fasad yang diterapkan berdasarkan beberapa pertimbangan yaitu :

1. Bangunan adalah sebuah objek wisata yang memiliki sifat rekreatif sehingga perlu memiliki perwajahan atau fasad yag menarik.

2. Bangunan adalah sebuah objek wisata yang terletak di pegunungan yang di sekitarnya terdapat alam yang asri dan alami. Sehingga perlu memiliki perwajahan atau fasad yang menyatu dengan keadaan alam di sekitarnya.

3. Bangunan adalah objek wisata yang mengusung Kambing Etawa sebagai ikon utama dari objek wisatanya. Sehingga ada baiknya menerapkan bantuk-bentuk yang menggambarkan objek ikonnya, sehingga akan terekesan lebih unik dan sedikit mewakili fungsi bangunan.

Sehingga berdasarkan pertimbanganpertimbangan di atas, maka konsep pengolahan fasad dari bangunanbangunan di kawasan wisata edukai peternakan kambing etawa akan menerapkan bentuk-bentuk yang mewakili peternakan dan atau mewakili kambing etawa.

\subsection{Analisis Utilitas Air dan Limbah}

Pemenuhan kebutuhan air bersih di kawasan objek wisata peternakan kambing etawa berasal dari sumur air yang dipompa ke atas permukaan tanah yang ditampung oleh tank.

Karena mayoritas bangunan di kawasan wisata adalah banguna berlantai 1 dan yang paling tinggi adalah berlantai 2 yaitu pengianpan, maka sistem distribuasi air bersih yang digunakan yaitu dengan menggunakan sistem down feed distribution untuk menghemat energy.

1. Kebutuhan untuk penginapan dan fasilitas wisata
Menggunakan sistem down feed, air bersih disalurkan menuju tangki yang berada di atas (rooftank) kemudian baru didistribusikan melalui pipa ke keran-keran.

2. Kebutuhan untuk kandang peternakan

Menggunakan sistem down feed, air bersih disalurkan menuju tangki yang berada di atas (rooftank) kemudian baru didistribusikan melalui pipa ke area kandang.

3. Kebutuhan untuk area outdoor

Air bersih disalurkan menuju groundtank kemudian didistribusikan melalui pipa-pipa kran selanjutnya disalurkan menggunakan sprinkler portabel.

Sistim Pembuangan air kotor :

1. Sistem pembuangan air kotor tidak mencemari lingkungan.

2. Pengelolaan sistem air kotor tidak mengganggu sumber air bersih didalam tanah.

3. Sistem jaringan air kotor meliputi air kotor, air hujan dan air buangan. Untuk air hujan dilakukan penampungan untuk dapat digunakan kembali.

Penerapan sistem ekologi pada pengolahan limbah adalah dengan mengadakan pengolahan sampah untuk dimanfaatkan kembali serta menjaga kebersihan lingkungan. Berikut adalah usaha-usaha yang dilakukan dalam pengelolaan limbah yaitu :

1. Penempatan tempat sampah atau box-box sampah harus diletakkan di tempat yang strategis, dengan memperhatikan posisi yang mudah dijangkau, terlihat dan dekat dengan kegiatan-kegiatan yang ada agar dapat didayagunakan sesuai keperluan yang ada.

2. Kegiatan pengolahan limbah peternakan menjadi pupuk adalah salah satu langkah untuk meminimalisasi adanya limbah yang dibuang ke alam. 
3. Untuk sampah organik dapat diolah menjadi pakan kambing atau dimanfaatkan menjadi pupuk kompos yang kemudian dimanfaatkan untuk memupuk kebun organik.

\section{KESIMPULAN DESAIN)}

(KONSEP

Objek Wisata Edukasi Peternakan Kambing Etawa di Kaligesing, Purworejo adalah sebuah objek wisata yang berlokasi di pegunungan dengan kondisi udara sejuk dan cenderung dingin. Objek ini berfungsi sebagai tempat wisata yang juga menyajikan pengetahuan tentang kegiatan peternakan kambing etawa yang dilengkapi dengan fasilitas menginap bagi pengunjung yang ingin lebih lama mendalami pengetahuan tetang peternakan kambing etawa serta lebih lama menikmati keindahan alam pegunungan di Kaligesing.

Konsep rancangan objek wisata ini mengacu pada prinsip Arsitektur Ekologis guna menjaga keberlanjutan dalam pemeeliharaan kelestarian lingkungan di Kaligesing. Terdapat beberapa poin yang diterapkan pada perancangan objek wisata edukasi ini yaitu :

1. Menciptakan kawasan hijau diantara kawasan bangunan

Pengolahan ruang hijau di objek wisata edukasi peternakan kambing etawa tidak hanya diperuntukan menjadi taman saja, namun juga ruang hijau untuk berkebun. Kabun organik ini diperuntukkan juga untuk pengujung yang ingin belajar tentang pengolahan pupuk organik dan aplikasinya. Dengan adanya kegiatan berkebun ini juga memberikan edukasi bagi pengunjung bahwa limbah peternakan, tidak hanya dibuang begitu saja ke alam, namun juga bisa diolah agar dapat dijadikan pupuk organik.

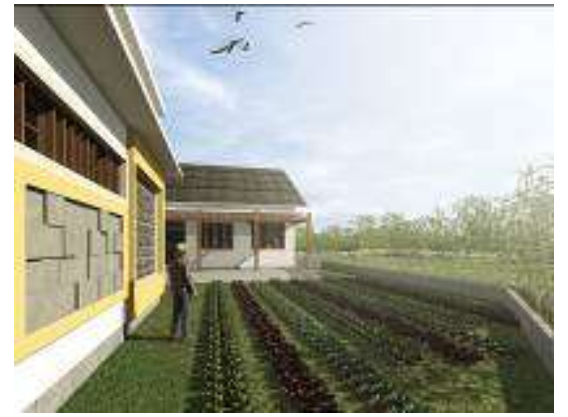

Gambar 7.Kebun Organik sebagai salah satu wahana edukasi (Desain Penulis)

2.Memilih tapak bangunan yang sesuai

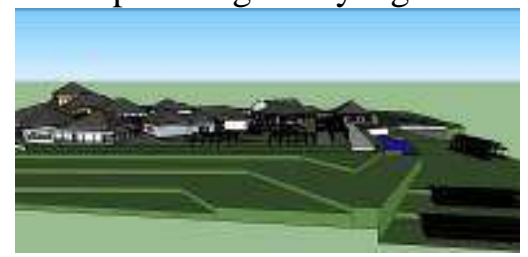

Gambar 8. Pengolahan Tapak (Desain penulis)

Pengolahan tapak disesuaikan dengan kegiatan di setiap area. Pada dataran yang lebih rendah yang berada di sisi site sebelah utara dipergunakan sebagai area peternakan.

3. Penghawaan dan pencahayaan alami serta penggunaan material lokal Penghawaan dan pencahayaan alami dihadirkan dalam bangunan untuk memaksimalkan energi alami yang dimiliki alam dengan penempatan bukaan yang tepat sesuai analisis klimatoligis bangunan. Pada bagian bangunan yang menghadap arah datang angin, diterapkan banyak bukaan, baik berupa jalusi maupun menggunakan roster. Selain itu, pada bangunan juga diterapkan penggunaan material alam lokal yaitu berupa batuan alam yang menghiasi dinding bangunan. 


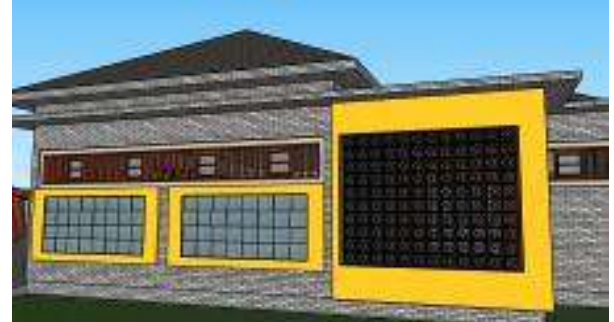

Gambar 9. Aplikasi material batuan dan bukaan sebagai penghawaan dan pencahayaan alami.

(Desain Penulis)

4. Orientasi bangunan ditempatkan diantara lintasan matahari dan angin sebagai kompromi antara letak gedung berarah dari timur ke barat, dan yang terletak tegak lurus terhadap arah angin.

Untuk

menanggulangi permasalahan bau dari peternakan, maka penataan tata massa bangunan selain disesuaikan dengan orientasi bangunan utama yang menghadap ke barat, arah hadap bangunan juga disesuaikan dengan arah datang dan pergi angin. Sehingga mayoritas bangunan diletakkan miring 30 derajat agar memudahkan angin yang mengalir dari arah barat laut ke tenggara.

Sebagai usaha pencegah polusi bagu serta penghijaun lingkungan, maka diberikan aplikasi green barrier pada area-area yang dimungkinakan terkena aliran udara dari peternakan.

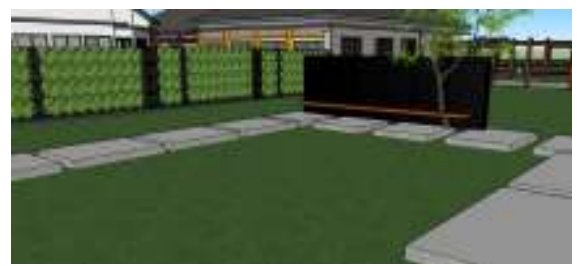

Gambar 10. Green Barier sebagai penyaring bau (Desain Penulis)

5. Menjamin bahwa bangunan tidak menimbulkan permasalahan lingkungan
Agar bau dari bangunan peternakan tidak mengganggu aktivitas di lingkungan sekitarnya, maka tata letak bangunan dibuat menyesuaikan peraturan persyaratan bangunan peternakan Sk.Dirjen Peternakan No: 776/Kpts/Djp/Deptan/1982 tentang Syarat-Syarat Teknis Perusahaan Peternakan Sapi Perah, yaitu menyatakan jarak minimal tiap bangunan pada peternakan adalah sebagai berikut :

a. Kandang dengan bangunan lain = 15 meter

b.Kandang isolasi terpisah dari kandang utama $=11$ meter

c. Pengolahan susu dengan kandang $=25$ meter

d.Pengolahan susu dengan pengolahan limbah $=100$ meter

Berdasarkan peraturan di atas maka desain yang dihaslikan adalah sebagai berikut :

a. Area peternakan atau area kandang kambing berada di area utara, sehingga saat angin berhembus, arah aliran angin tidak mengarah ke area wisata. Seperti pada ilustrasi di bawah.

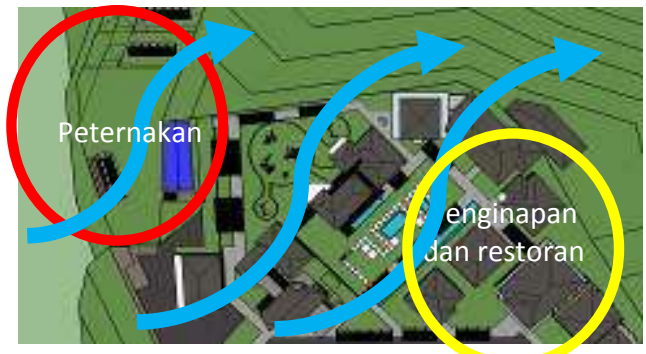

Gambar 11. Ilustrasi hembusan angin pada kawasan wisata

(Desain dan Anallisis Penulis)

b. Area peternakan secara vertical berada di dataran yang lebih rendah 5 meter dari dataran kawasan wisata. 


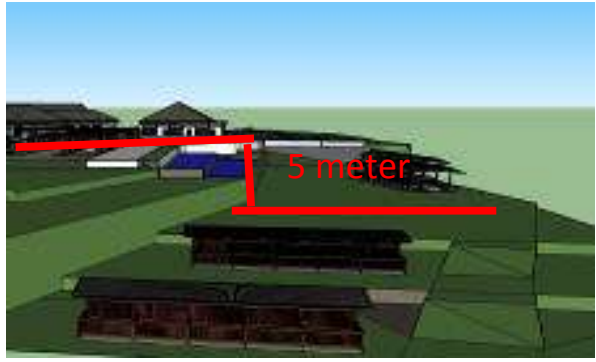

Gambar 12. Perbedaan dataran area peternakan

(Desain dan Analisis Penulis)

c. Area kandang kambing utama secara horizontal terhadap penginapan berada di jarak 160 meter terhadap restoran 150 meter

d. Area kandang kambing secara horizontal terhadap rumah edukasi bedara di jarak 70 meter

e. Area Kandang kambing secara horizontal dengan toko oleh-oleh berada di jarak 60 meter.

f. Area pengolahan limbah secara horizontal dengan bangunan penyimpanan susu berjarak 150 meter.

g. Kandang kambing utama dengan Kandang isolasi dan karantina berjarak 40 meter dengan penghalang pepohonan dengan rata-rata tinggi pohon 2-3 meter.

h. Respon desain khusus pad area perbatasan area wisata dengan area kandang yaitu dengan dibatasi pepohonan hijau dengan lebar 6 meter. Lalu 2 kolam ikan berundak masing-masing selebar 5 meter, sehingga lebar kolam totalnya 10 meter. Terakhir di dataran terendah diberikan pepohonan dengan lebar 3 meter. Jarak pepohonan menuju kandang adalah 16 meter. Total, lebar area penyaringan bau adalah 35 meter

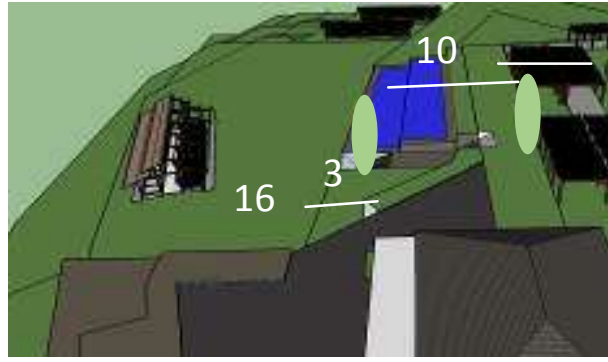

Gambar 13. Respon desain terkait bau peternakan

(Desain dan Analisis Penulis)

Untuk pengolahan limbah peternakan dilakukan dengan pengolahan urin dan kotoran kambing sebagai pupuk organik. Sehingga tidak dibuang dalam bentuk limbah, namun sudah terolah dan dijadikan produk yang bermanfaat bagi alam.

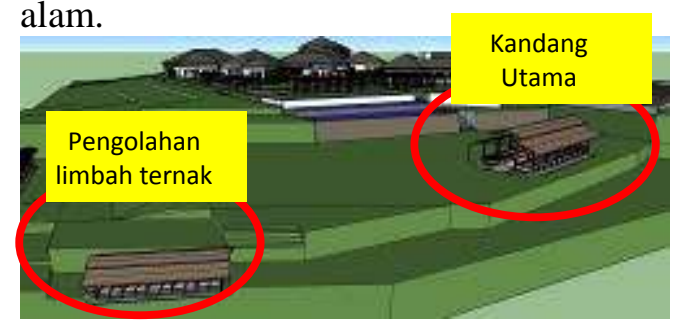

Gambar 14. Letak Bangunan pengolahan limbah

(Desain Penulis)

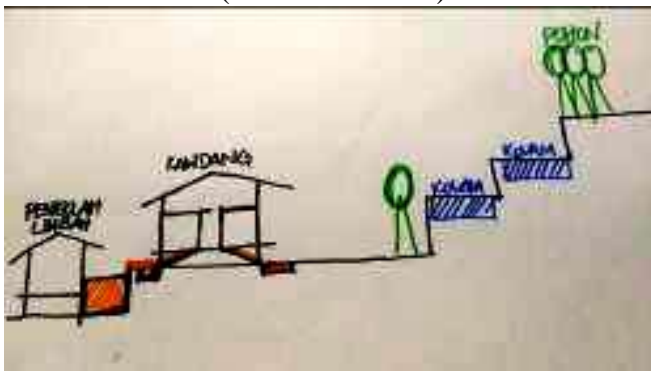

Gambar15. Aliran limbah urin dari kandang utama ke pengolahan limbah.

(Desain Penulis)

6. Menciptakan bangunan bebas hamtan (dapat digunakan semua umur dan pengguna difabel)

Sebagai usaha untuk menghadirkan kemudahan bagi pengunjung difabel maka pada beberapa titik bangunan diberikan jalur ramp.

\section{REFERENSI}

Frick H., dan FX Bambang Suskiyanto, (1998), Dasar-dasar Eko-arsitektur. Yogyakarta: Kanisius 
Setyaningsih W.,(2016). Transformasi Arsitektural Dari Kampung Kota Menjadi Kampung Wisata Studi Kasus : Kampung Wisata di Surakarta. Disertasi S3 Prodi Arsitektur FT UGM. Yogyakarta Republik Indonesia.1982.Sk.Dirjen Peternakan No: 776/Kpts/Djp/Deptan/1982 tentang Syarat-Syarat Teknis Perusahaan Peternakan Sapi Perah.Jakarta http://KRJogja.com/23/8/-Bibit-LarangJual-Kambing-PE-ke-Lar-Negri.html diakses 11 Mei 2016 